\title{
Notes on the vocalizations of Lesser Bristlebill (Bleda notatus)
}

Peter Boesman

In the following we briefly analyze and compare voice of the two races of Lesser Bristlebill (Bleda notatus). We also try to quantify the extent of any vocal differences using the criteria proposed by Tobias et al. (2010), as a support for taxonomic review. We have made use of sound recordings available on-line from Xeno Canto (XC) and Macaulay Library (ML).

An overview of vocalizations based on available recordings:

ugandae

Song-like vocalization which can be transcribed as: 'chow-chow-chow-chowee-chowee'

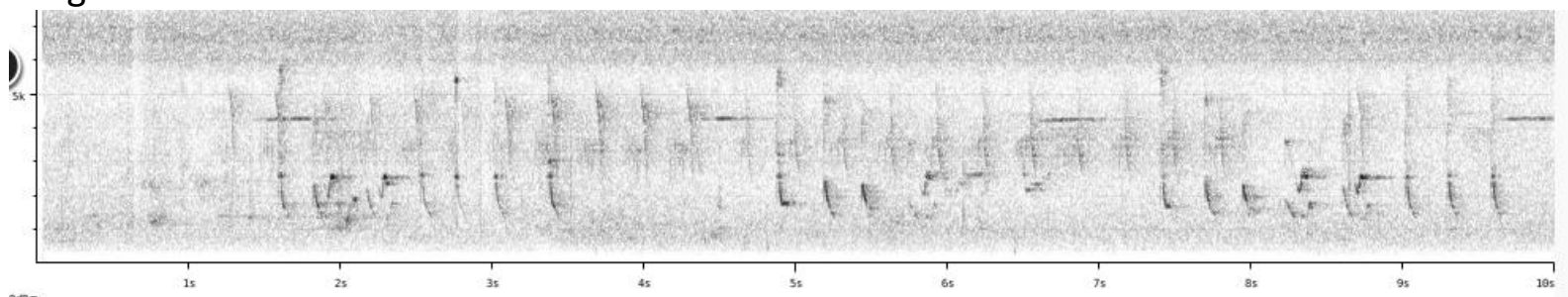

Song-like vocalization which can be transcribed as: 'chow-chow-chow..' and 'chow-chow-chotrrrrrr'

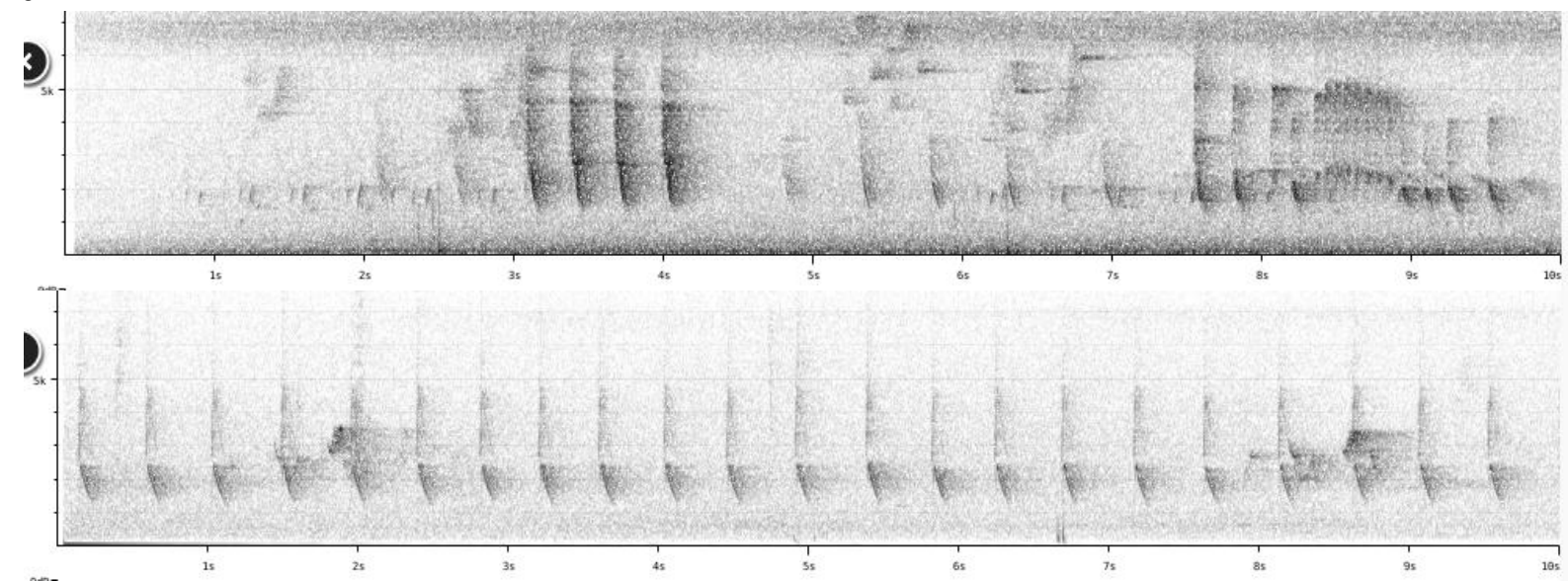

Call: a fast rattle

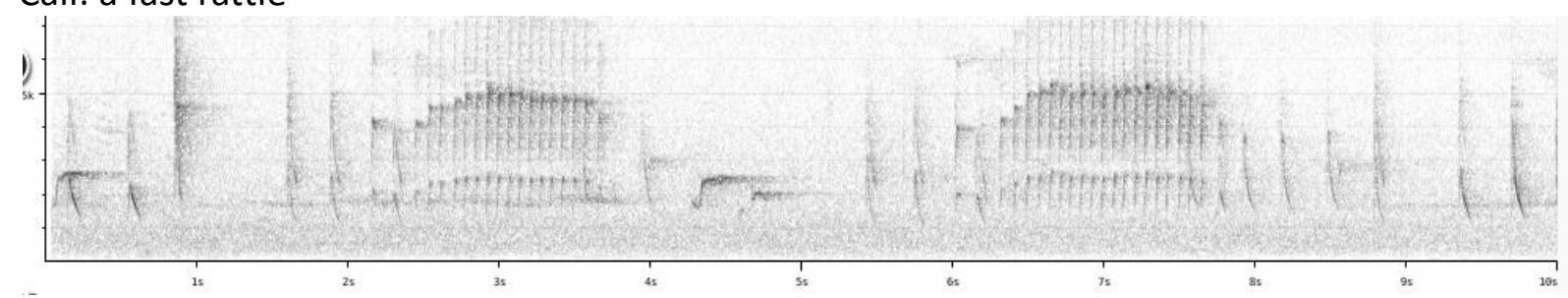



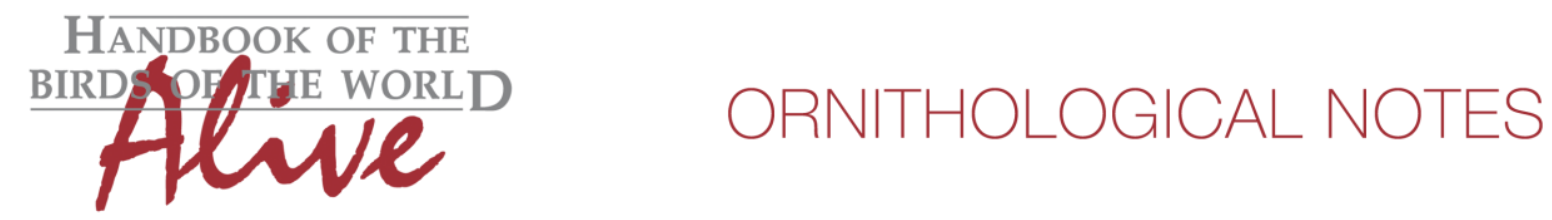

notatus

Song-like vocalization which can be transcribed as: 'chee-cheewhu' and 'chee-cheewhuchup-chee' etc., occasionally followed by a series of tremulous whistles (true song?).

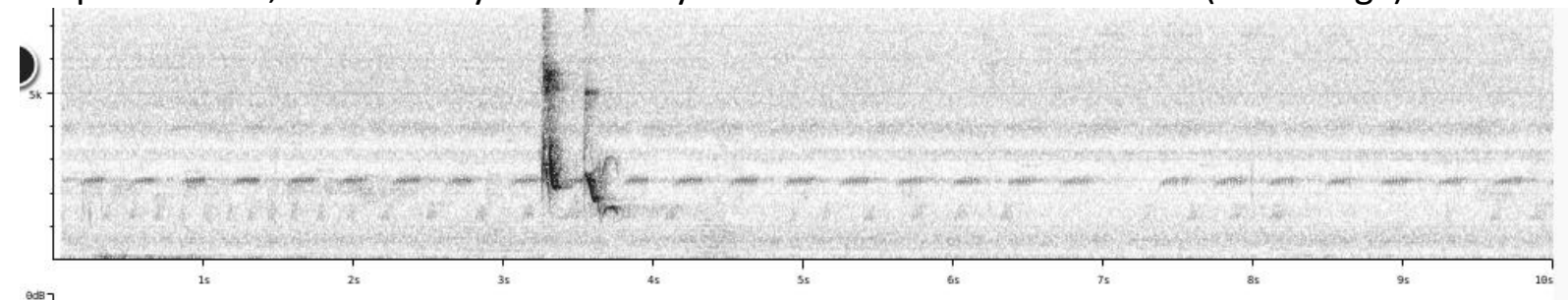

Song-like vocalization which can be transcribed as: 'chee-cheewhu-cheewhu'

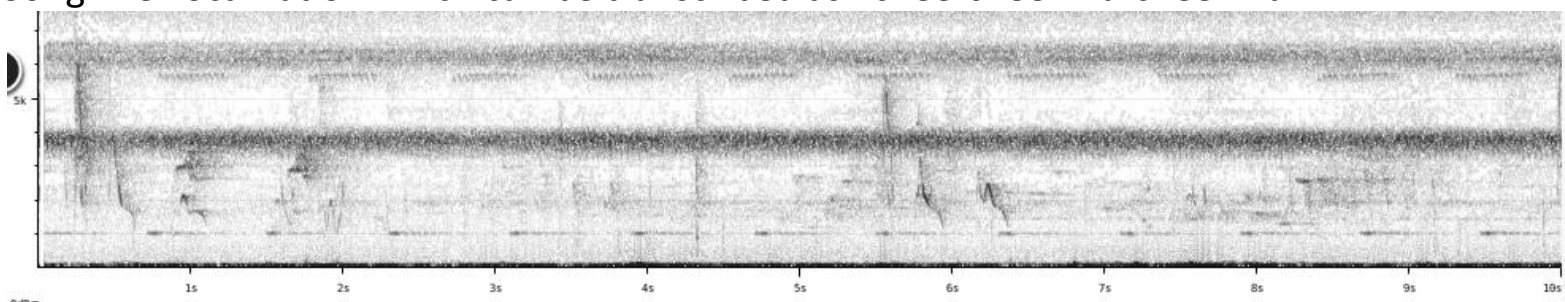

Call: a fast rattle

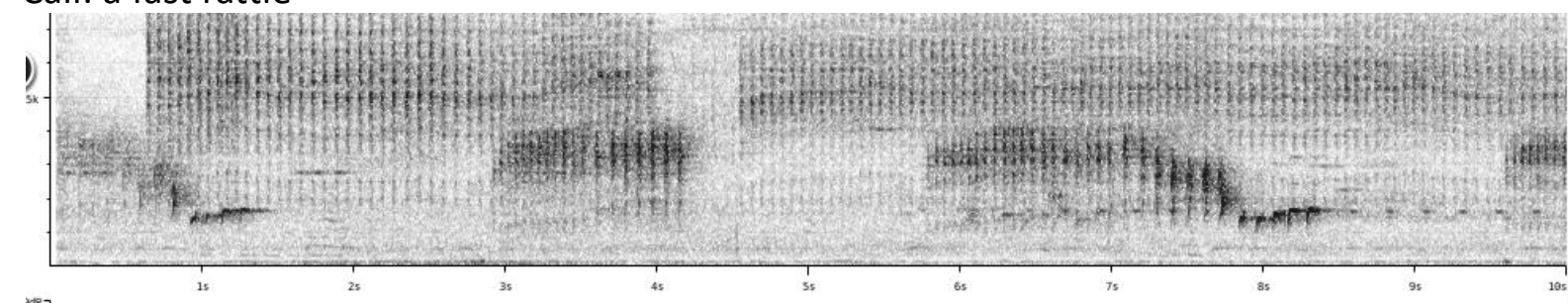

Song-like vocalization of both races is clearly different, while the rattle call is rather similar. The former is easily assigned to either race, but basic sound parameters are rather similar. Differences lie in note shapes, number of repeats and phrase compositions:

- ugandae typically repeats same note from several to many times, notatus repeats at most twice (score 2).

- note shape of principal note in ugandae a simple clear-cut descending 'chow', versus more complex notes in notatus (score 1 )

When applying Tobias criteria, this would lead to a total vocal score of (at least) 3.

This note was finalized on 18th February 2016, using sound recordings available on-line at that moment. We would like to thank in particular the sound recordists who placed their recordings for this species on XC and ML: James Bradley, Jacob Cooper, Linda Macaulay, Erik Eggenkamp, David Moyer, Mike Nelson, Bram Piot, Mark Robbins, Paul Rodewald and Martin St-Michel.

\section{References}

Fishpool, L. \& Tobias, J. (2016). Lesser Bristlebill (Bleda notatus). In: del Hoyo, J., Elliott, A., Sargatal, J., Christie, D.A. \& de Juana, E. (eds.). Handbook of the Birds of the World Alive. Lynx Edicions, Barcelona. (retrieved from http://www.hbw.com/node/58005 on 18 February 2016). 
Tobias, J.A., Seddon, N., Spottiswoode, C.N., Pilgrim, J.D., Fishpool, L.D.C. \& Collar, N.J. (2010). Quantitative criteria for species delimitation. Ibis 152(4): 724-746.

\section{Recommended citation}

Boesman, P. (2016). Notes on the vocalizations of Lesser Bristlebill (Bleda notatus). HBW Alive Ornithological Note 240. In: Handbook of the Birds of the World Alive. Lynx Edicions, Barcelona. (retrieved from http://www.hbw.com/node/932237 on 30 September 2016). 